LXIV.-Experiments on the Synthesis of the Terpenes. Part II. Synthesis of $\Delta^{3}-\mathrm{p}-$ Menthenol(8), $\Delta^{3.8(9)}-\mathrm{p}-$ Menthadiene, p-Menthanol(8), $\Delta^{\mathrm{s}(9)}-\mathrm{p}-$ Menthene, and p-Menthane.*

By William Henry Perkin, jun., and Samuel Shrowder Pickles. The first paper on this subject (Perkin, Trans., 1904, 85, 654) dealt with the conversion of $\Delta^{3}$-tetrahydro-p-toluic acid into terpineol, dipentene, and terpin, a series of changes which may conveniently be represented thus :

$\Delta^{3}$-Tetrabydro-p-toluic acid, $\mathrm{Me} \cdot \mathrm{C}<\frac{\mathrm{CH}_{2}}{\mathrm{CH}_{2}-\mathrm{CH}_{2}}>\mathrm{CH} \cdot \mathrm{CO}_{2} \mathrm{H}$.

Terpineol, $\mathrm{Me} \cdot \mathrm{C}<\frac{\mathrm{CH}_{2} \cdot \mathrm{CH}_{2}}{\mathrm{CH}-\mathrm{CH}_{2}}>\mathrm{CH} \cdot \mathrm{CMe}_{2} \cdot \mathrm{OH}$.

Dipentene, $\mathrm{Me} \cdot \mathrm{C}<\mathrm{CH}_{2} \cdot \mathrm{CH}_{2}>\mathrm{CH} \cdot \mathrm{CH} \underset{\mathrm{Me}}{\mathrm{CH}} \cdot \underset{\mathrm{CH}_{2}}{\mathrm{CH}_{2}}$

Terpin, $\mathrm{Me} \cdot \mathrm{C}(\mathrm{OH})<\mathrm{CH}_{2} \cdot \mathrm{CH}_{2}>\mathrm{CH} \cdot \mathrm{CMe}_{2} \cdot \mathrm{OH}$.

The present paper deals, in the first place, with some hitherto unknown members of the torpene series which have been synthesised by employing $\Delta^{1}$-tetrahydro-p-toluic acid, instead of the $\Delta^{3}$-tetrahydroacid, in experiments similar to those which led to the syntheses just mentioned.

$$
\Delta^{1} \text {-Tetrahydro-p-toluic acid, } \mathrm{Me} \cdot \mathrm{CH}<\underset{\mathrm{CH}_{2}}{\mathrm{CH}_{2}-\mathrm{CH}_{2}}>\mathrm{CH} \cdot \mathrm{CO}_{2} \mathrm{H} \text {, }
$$

has already been obtained by Einhorn and Willstätter (Annalen, 1894, 280, 163) from $a$-bromohexahydro-p-toluic acid by treatment with quinoline. We prepared this acid in quantity by a modification of the above method (p. 645) and converted it into ethyl tetrahydro- $p$-toluate by the action of alcohol and sulphuric acid.

This ester reacts readily with an ethereal solution of magnesium methyl iodide yielding

$$
\Delta^{3}-p \text {-menthenol(8), } \mathrm{Me} \cdot \mathrm{CH}<\mathrm{CH}_{2} \cdot \mathrm{CH}_{2}{ }_{2}-\mathrm{CH}_{2} \cdot \mathrm{CMe}_{2} \cdot \mathrm{OH},
$$

* The system of nomenclature used in the papers of this series is that employed in the excellent account of the terpenes written for Meyer-Jacobson's Lehrbuch (Vol. II, i, pp. 876-962) by Prof. Carl Harries.

The basis of this system is hexahydrocymene and the numbering, in the ease of the $p$-series,

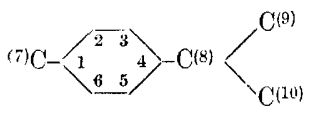

is that recommended by Baeyer (Ber., 1894, 27, 43b). 
which is isomeric with terpineol ( $\Delta^{1}-p$-menthenol-8) and differs, indeed, from this substance only in the position of the double linking in the ring, as a comparison of their formulæ will show.

It was therefore interesting to find that this new menthenol resembles terpineol, not only in odour, but also in many other properties.

Thus, when digested with potassium hydrogen sulphate, it is converted by loss of water into

$$
\Delta^{3.8(9)} p \text {-menthadiene, } \mathrm{Me} \cdot \mathrm{CH}<\underset{\mathrm{CH}_{2}}{\mathrm{CH}_{2}-\mathrm{CH}_{2}}>\mathrm{CH} \cdot \mathrm{C}<{ }_{\mathrm{Me}}{ }_{2} \text {, }
$$

just as terpineol, under the same conditions, yields dipentene.

On the other hand, terpineol is a solid, crystalline substance, whereas $\Delta^{3}-p$-menthenol(8) is liquid, and we have not been able to prepare from the latter a crystalline nitrosochloride or phenylurethane corresponding to these well known derivatives of terpineol. One of the most characteristic properties of terpineol is its conversion into terpin hydrate by the action of dilute sulphuric acid at the ordinary temperature, * but, although very careful experiments were made on the subject, there was no indication of any similar addition of water taking place when the new menthenol was subjected to exactly similar treatment. These differences in properties, due obviously to difference in the position of the double linking in the ring, are, perhaps, greater than might have been expected from so small a change in constitution. As stated above, $\Delta^{3}-p$-menthenol(8), when digested with potassium hydrogen sulphate, yields $\Delta^{3.8(9)}-p$-menthadiene, and the properties of this new hydrocarbon are very interesting, especially when compared with those of dipentene $\left(\Delta^{1.8(9)}-p\right.$-menthadiene), from which it differs only in the position of the double linking in the ring.

$\Delta^{3.8(9)}-p$-Menthadiene distils at $186-187^{\circ}$, or a few degrees higher than dipentene $\left(181^{\circ}\right)$, and it possesses in an even more marked degree the odour of lemons so characteristic of the latter; apparently then this odour is not as:ociated with any definite position of the double linking in the ring. In several other respects, however, the new terpene has properties which are very different from those of dipentene. The latter hydrocarbon yields a crystalline nitrosochloride, $\mathrm{C}_{10} \mathbf{H}_{16}, \mathrm{NOCl}$, and hydrochloride, $\mathrm{C}_{10} \mathrm{H}_{16}, 2 \mathrm{HCl}$, and is especially characterised by its behaviour towards bromine, with which it combines to form a crystal-

* In part I of this research (loc. eit., p. 667), I ascribed to Tiemann and Schmidt (Ber., 1895, 28, 1781) the important discovery of the conversion of terpineol into terpin hydrate by the action of dilute sulphuric acid at the ordinary temperature. Prof. Wallach has kindly pointed out that the discovery was first made by Tilden (Trans., 1879, 35, 289) and confirmed by himself (Annalen, 1885, 230, 266) several years before the appearance of the paper by Tiemann and Schmidt.

-W. H. Perkin, jun. 
line tetrabromide, $\mathrm{C}_{10} \mathrm{H}_{16} \mathrm{Br}_{4}$ The new terpene reacts with Oiew Online chloride and with hydrogen chloride, yielding oily products which were not further investigated, but the most striking property which it exhibits is that it is capable of combining with only two atoms of bromine to form an unstable dibromide of the formula $\mathrm{C}_{10} \mathrm{H}_{16} \mathrm{Br}_{2}$.

In this respect, then, the new terpene differs in a marked way from dipentene, and since both hydrocarbons are represented by formulæ containing two double linkings, this difference in behaviour appeared, at first, difficult to understand.

If, however, the formula of

$$
\Delta^{3.8(9)} p \text {-menthadiene, } \mathrm{Me} \cdot \mathrm{CH}<\mathrm{CH}_{2} \cdot \mathrm{CH}_{2}-\mathrm{CH}_{2}>\mathrm{C} \cdot \mathrm{C}<_{\mathrm{Me}^{2}}^{\mathrm{CH}_{2}} \text {, }
$$

is examined, it will be seen that the two double linkings are in the position $-\mathrm{C}: \mathrm{C} \cdot \mathrm{C}: \mathrm{C}-$, and it has long been known that substances containing this grouping are only capable of uniting with two atoms of bromine to form derivatives in which that grouping becomes - $\mathrm{CBr} \cdot \mathrm{C}: \mathrm{C} \cdot \mathrm{CBr}-($ compare especially Baeyer and Herb, Annalen, 1890, 258, 2 ; Thiele, Annalen, 1898, 306, 87 ; 1901, 319, 129). There can be no doubt that, in combining with two atoms of bromine, $\Delta^{3.8(9)}-p$-menthadiene yields a dibromo-additive product of the formula

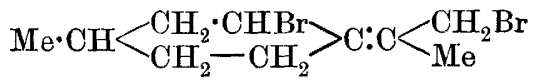

(3: 9 -dibromo- $\Delta^{4(8)}-p$-menthene), and that this substance is incapable of combining further with bromine without elimination of hydrogen bromide.

Similar results to the above were obtained in our experiments

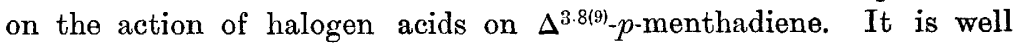
known that dipentene, $\mathrm{C}_{10} \mathrm{H}_{16}$, combines readily with two molecules of both hydrogen chloride and hydrogen bromide to yield the well characterised crystalline derivatives $\mathrm{C}_{10} \mathrm{H}_{16}, 2 \mathrm{HCl}$ and $\mathrm{C}_{10} \mathrm{H}_{16}, 2 \mathrm{HBr}$.

When $\Delta^{3.8(9)}-p$-menthadiene is subjected to the action even of a very large excess of either of these reagents, it is only capable of combining with one molecule of each, yielding the liquid additive compounds $\mathrm{C}_{10} \mathrm{H}_{16}, \mathrm{HCl}$ and $\mathrm{C}_{10} \mathrm{H}_{16}, \mathrm{HBr}$.

Experiments which are in progress seem to indicate that all terpenes which contain the grouping $-\mathrm{C}: \mathrm{C} \cdot \mathrm{C}: \mathrm{C}$ - will be found to behave in a similar manner and to combine witb only two atoms of bromine and one molecule of a halogen acid. The behaviour towards bromine and halogen acids may, therefore, in future prove to be of the highest importance in assigning a constitutional formula to a new terpene.

Included in the present paper are two other series of experiments, namely, the preparation of $p$-menthanol $(8), \Delta^{8(9)}$-p-menthene, and 
$p$-menthane from ethyl hexahydro- $p$-toluate, and of $p$-tolyldimethylcarbinol and $p$-methylisopropenylbenzene from ethyl $p$-toluate itself.

When ethyl hexahydro-p-toluate is allowed to react at the ordinary temperature with an ethereal solution of magnesium methyl iodide, it is converted into

$$
\text { p-menthanol(8), } \mathrm{Me} \cdot \mathrm{CH}<\mathrm{CH}_{2} \cdot \mathrm{CH}_{2}>\mathrm{CH}_{2}>\mathrm{CH} \cdot \mathrm{CMe}_{2} \cdot \mathrm{OH} \text {, }
$$

a crystalline substance which melts at $36^{\circ}$, distils at $207^{\circ}$, is volatile at the ordinary temperature, and has a penetrating odour of peppermint, properties which are almost identical with those of

$$
\text { menthol ( } p \text {-menthanol-3), } \mathrm{Me} \cdot \mathrm{CH}<\mathrm{CH}_{2}-\mathrm{CH}_{2} \cdot \mathrm{CH}\left(\mathrm{OH}_{2}\right)>\mathrm{CH} \cdot \mathrm{CM}_{2} \mathrm{H} \text {, }
$$

from which it differs only in the position of the hydroxyl group. Besides menthol itself, three other menthanols are known, all of which contain the hydroxy-group in the ring, namely, tertiary carvomenthol(1), carvomenthol(2), and tertiary menthol(4), the numbers after the names indicating the position of the hydroxyl groups.

$p$-Menthanol(8) appears to be the first derivative of $p$-menthane, so far prepared, in which the hydroxy-group is situated in the isopropyl side chain. When $p$-menthanol(8) is heated with potassium hydrogen sulphate, it is decomposed with elimination of water and formation of

$$
\Delta^{\mathrm{s}(9)} \text {-p-menthene, } \mathrm{Me} \cdot \mathrm{CH}<\mathrm{CH}_{2} \cdot \mathrm{CH}_{2}>\mathrm{CH} \cdot \mathrm{C}<_{\mathrm{Me}} \mathrm{CH}_{2},
$$

a hydrocarbon which distils at $170^{\circ}$ and has a faint odour resembling parsley and quite different from that of dipentene or $\Delta^{3.8(9)}-p$-menthadiene. This fact is interesting, because $\Delta^{8(9)}-p$-menthene is a dihydro-derivative of both these hydrocarbons, and in each case the formation of the dihydro-derivative has resulted in the disappearance of the double linking in the ring, and with this change in constitution the intense odour of lemons so characteristic of both has also disappeared. Besides the new hydrocarbon just described, only two of the six possible $p$-menthenes seem to have been prepared, namely, $\Delta^{1}$-p-menthene (carvomenthene) and $\Delta^{3}-p$-menthene. The latter may be readily obtained in quantity, as Zelinsky and Zelikoff (Ber., 1901, 34, 3253) have shown, by heating menthol with oxalic acid. It is very similar in properties to $\Delta^{8(9)}-p$-menthene, and like this substance has only a feeble odour. Both $\Delta^{3}-p$-menthene and $\Delta^{8(9)}-p$-menthene are dihydro-derivatives of $\Delta^{3.8(9)}-p$-menthadiene; in the first case, the double linking in the side chain, and in the second that in the ring has been removed by the addition of two atoms of hydrogen. Since in both cases this change has resulted in the disappearance of the characteristic odour of lemons, it would seem to follow that this odour is dependent 
on the presence both of the double linking in the ring and of that in the side chain.

$\Delta^{8(9)}-p$-Menthene is reduced with difficulty, even when dissolved in alcohol and treated with a large excess of sodium, but if its hydrobromide, $\mathrm{C}_{10} \mathrm{H}_{16}, \mathrm{HBr}$, is treated with zinc dust and acetic acid it is converted into

$$
p \text {-menthane (hexahydrocymene), } \mathrm{Me} \cdot \mathrm{CH}<\underset{\mathrm{CH}_{2}}{\mathrm{CH}_{2} \cdot \mathrm{CH}_{2}}>\mathrm{CH} \cdot \mathrm{CMe}_{2} \mathrm{H} \text {. }
$$

This hydrocarbon had previously been obtained by several methods (see p. 652); it distils at $169-170^{\circ}$ and has a rather feeble odour resembling that of light petroleum.

While considering the properties of the members of the terpene group which we had synthesised by the reactions mentioned above, some of which are derived from tetrahydro- and some from hexahydrobenzene, it occurred to us that it would be interesting to compare their properties with those of similarly constituted substances containing in the place of the reduced rings the benzene ring itself. We therefore treated ethyl $p$-toluate with magnesium methyl iodide and obtained a good yield of $p$-tolyldimethylcarbinol, $\mathrm{Me} \cdot \longrightarrow \cdot \mathrm{CMe}_{2} \cdot \mathrm{OH}$, a tertiary alcohol which had not previously been described.

This substance is a liquid which distils at $112^{\circ}(16 \mathrm{~mm}$.) and has a rather pleasant sweet odour, quite distinct from that of terpineol or any other similarly constituted alcohol belonging to the terpene group. When this alcohol is digested with potassium hydrogen sulphate, it is decomposed in the usual manner with elimination of water and formation of $p$-methylisopropenylbenzene,

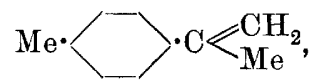

a hydrocarbon of which dipentene and $\Delta^{3.899}-p$-menthadiene are the tetrahydro-derivatives. It boils at $187^{\circ}$ and possesses an odour very similar to that of cinnamene, and quite unlike that of a terpene; it combines with two atoms of bromine with formation of a liquid additive product, and yields a crystalline nitrosochloride which melts at $102^{\circ}$.

\section{Reduction of p-Toluic Acid.}

In preparing hexahydro- $p$-toluic acid, $p$-toluic acid, in quantities of 10 grams, was dissolved in isoamgl alcohol (500 c.c.) and reduced at the boiling temperature with sodium (50 grams), essentially according to the method recommended by Einhorn and Willstätter (Annalen, 1894, $280,160)$. The product was shaken with twice its volume of water, the aqueous solution separated from the isoamyl alcohol, nearly neutralised 
with dilute sulphuric acid, and evaporated to a small bulk Online acidifying and extracting with ether in the usual way, the crude crystalline acid was dissolved in dilute sodium carbonate and oxidised with permanganate at $0^{\circ}$ until the colour remained permanent, a stream of carbon dioxide being passed during the whole operation. By this means, the hexahydro-acid is freed from unsaturated acids (probably tetrahydro-p-toluic acids) which are always present. The filtrate from the manganese precipitate was evaporated, acidified, and extracted with ether, and the extract several times fractionated in order to separate the hexahydro-acid from considerable quantities of isovaleric acid. Lastly, the distilled acid was left in contact with porous porcelain until all oily impurity bad been absorbed. Hexahydro- $p$-toluic acid melts at $112^{\circ}$ and crystallises from formic acid in glistening prisms.

Ethyl Hexahydro-p-toluate.-In preparing this ester, the pure acid (38 grams) was dissolved in a cold mixture of ethyl alcohol (200 c.c.) and sulphuric acid (20 c.c.) and, after standing for two days, heated on the water-bath for one hour. Water was then added, the oily ester extracted with ether, the ethereal solution washed with water and dilute sodium carbonate, dried over calcium chloride, and evaporated. On distilling the residue, almost the whole quantity passed over at $207-208^{\circ}(737 \mathrm{~mm}$.) as a colourless oil having an unpleasant odour somewhat resembling that of amyl acetate.

0.2060 gave $0.5350 \mathrm{CO}_{2}$ and $0.1960 \mathrm{H}_{2} \mathrm{O} . \quad \mathrm{C}=70.8 ; \mathrm{H}=10 \cdot 7$. $\mathrm{C}_{10} \mathrm{H}_{18} \mathrm{O}_{2}$ requires $\mathrm{C}=70.6 ; \mathrm{H}=10.6$ per cent.

The yield of ester was 32 grams, and the unchanged acid was readily recovered from the sodium carbonate washings by acidifying and extracting with ether.

\section{Bromination of Hexahydro-p-toluic Acid.}

According to Einhorn and Willstätter (Annalen, 1894, 280, 161), hexahydro- $p$-toluic acid is not easily brominated by the Hell-Volhard process, and they therefore heated the acid first with phosphorus pentachloride and then with bromine in a sealed tube for three hours at $150^{\circ}$, or ten hours at $100^{\circ}$. The product was a black, tarry mass, from which, by repeated crystallisation, they were able to isolate pure $\alpha$-bromohexahydro- $p$-toluic acid. As we required large quantities of the bromo-acid, and the employment of sealed tubes was very inconvenient, we re-investigated the matter, and found that, although the bromination takes rather longer than is usually the case with acids of this nature, it can be carried out almost quantitatively and without the formation of any tarry products if the following conditions are observed. Hexahydro- $p$-toluic acid (21 grams), contained in a flask 

fitted with a ground-in condenser, is mixed with phosphorus pentachloride (42 grams), allowed to stand until the somewhat vigorous action has subsided, and then heated on the water-bath for about a quarter of an hour in order to complete the decomposition. Bromine (30 grams) is then added, and the heating continued for about two days and until the bromine has almost completely disappeared. The product is mixed with four times its volume of formic acid (sp. gr. 1.22), heated on the water-bath for half an hour, and then allowed to stand for 24 hours, when an almost colourless, crystalline cake of $\alpha$-bromohexahydro- $p$-toluic acid will have separated. This is collected at the pump, drained on porous porcelain, and is then almost pure.

For reasons explained in the next section, we preferred in most of our experiments to employ ethyl $a$-bromohexahydro-p-toluate rather than the acid and this ester, which had not previously been described, we prepared in large quantities in the following manner. The oily product of the bromination of hexahydro- $p$-toluyl chloride, obtained as described above, was poured into excess of alcohol, and, after standing for some hours, water was added and the heavy oil extracted with ether. The ethereal solution was well washed with water and dilute sodium carbonate, dried over calcium chloride, evaporated, and the residue fractionated under reduced pressure, when ethyl a-bromohexahydro$p$-toluate was obtained as a colourless oil which possessed a pungent and disagreeable odour, and distilled constantly at $144^{\circ}(50 \mathrm{~mm}$.). Owing, doubtless to some hydrogen bromide being eliminated during distillation, the analytical numbers obtained were somewhat lower than the theoretical.

\subsection{6 gave $0.1516 \mathrm{AgBr} . \quad \mathrm{Br}=31 \cdot 1$}

$$
\mathrm{C}_{10} \mathrm{H}_{17} \mathrm{O}_{2} \mathrm{Br} \text { requires } \mathrm{Br}=32 \cdot 1 \text { per cent. }
$$

\section{$\Delta^{1}$-Tetrahydro-p-toluic Acid.}

In our first experiments, this acid was prepared according to the directions given by Einhorn and Willstätter (Annalen, 1894, 280, $163)$, namely, by heating $\alpha$-bromohexahydro-p-toluic acid with quinoline, and purifying the resulting crude tetrahydro-acid by recrystallisation from dilute alcohol. We, however, subsequently found that the following process was much more convenient and gave a much better yield of the pure tetrahydro-acid. Powdered caustic potash (20 grams) is dissolved in hot methyl alcohol and, after cooling to about $40^{\circ}$, ethyl $a$-bromohexahydro- $p$-toluate ( 23 grams) is added; in a short time, the temperature rises to the boiling point and much potassium bromide separates. After heating on the water-bath for half an hour, the product is diluted with water, evaporated until free from alcohol, cooled and acidified, when tetrahydro- $p$-toluic acid separates in almost 
colourless crystals. These were collected at the pump and View Online recrystallisation from formic acid or dilute acetic acid.

0.1698 gave $0.4266 \mathrm{CO}_{2}$ and $0.1296 \mathrm{H}_{2} \mathrm{O} . \quad \mathrm{C}=68.5 ; \mathrm{H}=8.5$. $\mathrm{C}_{8} \mathrm{H}_{12} \mathrm{O}_{2}$ requires $\mathrm{C}=68.6 ; \mathrm{H}=8.6$ per cent.

$\Delta^{1}$-Tetrahydro-p-toluic acid crystallises in long, striated, prismatic needles, which melt at $134^{\circ}$; when heated under reduced pressure, the acid distils without decomposition.

Ethyl $\Delta^{1}$-Tetrahydro-p-toluate, $\mathrm{C}_{7} \mathrm{H}_{11} \cdot \mathrm{CO}_{2}$ Et. - In preparing this ester, the tetrahydro-acid (43 grams) was added to a mixture of alcohol (200 c.c.) and sulphuric acid (20 c.c.) and the mixture warmed on the water-bath until the crystals had completely dissolved. After standing for two days and heating on the water-bath for half an hour, water was added and the oily ester extracted with ether. The ethereal solution was washed with water and dilute sodium carbonate, dried over calcium chloride and evaporated, and the residue purified by distillation, when almost the whole quantity passed over at $152-153^{\circ}$ $(100 \mathrm{~mm}$.), the yield being nearly quantitative.

0.2194 gave $0.5746 \mathrm{CO}_{2}$ and $0.1902 \mathrm{H}_{2} \mathrm{O} . \quad \mathrm{C}=71.4 ; \mathrm{H}=9.6$. $\mathrm{C}_{10} \mathrm{H}_{16} \mathrm{O}_{2}$ requires $\mathrm{C}=71 \cdot 4 ; \mathrm{H}=9.5$ per cent.

Ethyl $\Delta^{1}$-tetrahydro-p-toluate is a colourless oil possessing a pungent odour somewhat resembling that of amyl acetate.

2-Bromohexchydro-p-toluic Acid.-Finely powdered tetrahydro-p-toluic acid dissolves readily in fuming hydrobromic acid (saturated at $0^{\circ}$ ) and the solution gradually deposits crystals of the above bromo-acid. After two days, these were collected and recrystallised from formic acid, from which the acid separates in glistening crystals.

0.2053 gave $0 \cdot 1732 \mathrm{AgBr} . \quad \mathrm{Br}=35 \cdot 9$.

$$
\mathrm{C}_{8} \mathrm{H}_{13} \mathrm{O}_{2} \mathrm{Br} \text { requires } \mathrm{Br}=36 \cdot 2 \text { per cent. }
$$

2-Bromohexahydro-p-toluic acid is very readily soluble in alcohol, benzene, ether, or chloroform, but sparingly so in light petroleum.

It crystallises well from dilute alcohol in microscopic needles.

1 : 2-Dibromohexahydro-p-toluic Acid, $\mathrm{C}_{7} \mathrm{H}_{11} \mathrm{Br}_{2} \cdot \mathrm{CO}_{2} \mathrm{H}$. - The solution of tetrahydro- $p$-toluic acid in chloroform is only very slowly attacked by bromine, but, if the powdered acid is left exposed to dry bromine vapour, addition takes place readily and completely.

The product was exposed over caustic potash until the free bromine had been removed and then crystallised from formic acid.

$0 \cdot 2282$ gave $0.2858 \mathrm{AgBr} . \quad \mathrm{Br}=53 \cdot 3$.

$$
\mathrm{C}_{8} \mathrm{H}_{12} \mathrm{O}_{2} \mathrm{Br}_{2} \text { requires } \mathrm{Br}=53 \cdot 3 \text { per cent. }
$$

1: 2-Dibromohexahydro-p-toluic acid melts at $149^{\circ}$, but softens some- 
what below this temperature; it is readily soluble in alcohol, ether, or benzene, but sparingly so in light petroleum. When the finely divided acid is shaken with sodium carbonate solution, it is converted into a sparingly soluble sodium salt which crystallises well from water but was not further investigated.

\section{$\Delta^{3}$-p-Menthenol(8).}

The method employed in preparing this tertiary alcohol was as follows: dry magnesium powder (18 grams) * was suspended in pure dry ether (distilled first over sodium and then over phosphoric anhydride) in a large flask connected with a long, reflux condenser and then methyl iodide (100 grams) added in three portions, any violent ebullition being controlled by plunging the flask into running water. When the magnesium had dissolved, ethyl tetrahydro- $p$-toluate (40 grams) was poured in, when it was noticed that very little rise of temperature occurred during the first few minutes, but that the ether gradually became heated to its boiling point if care was not taken to keep the flask well cooled. After 12 hours, the product was cautiously decomposed by water and dilute hydrochloric acid, the ethereal solution separated, washed with water, evaporated, and digested with methyl-alcoholic potash (10 grams $\mathrm{KOH}$ ) for 10 minutes on the water-bath, by which means any unchanged ester which might have been present was hydrolysed.

After diluting with water, the neutral oil was extracted with ether, the ethereal solution washed well, dried over calcium chloride and evaporated, and the residue distilled under reduced pressure $(30 \mathrm{~mm}$.). By far the larger portion passed over at $90-95^{\circ}$ and consisted of almost pure $\Delta^{3 \cdot s(\theta)}-p$-menthadiene (see the next section) and the remainder distilled at $110-135^{\circ}$. On refractioning the latter, an oil was obtained which distilled at $117-120^{\circ}(25 \mathrm{~mm}$.) and consisted of pure $\Delta^{3}$-p-menthenol(8).

$0 \cdot 1412$ gave $0.0431 \mathrm{CO}_{2}$ and $0 \cdot 1498 \mathrm{H}_{2} \mathrm{O} . \quad \mathrm{C}=77 \cdot 8 ; \mathrm{H}=11 \cdot 8$. $\mathrm{C}_{10} \mathrm{H}_{18} \mathrm{O}$ requires $\mathrm{C}=77.9 ; \mathrm{H}=11.7$ per cent.

$\Delta^{3}$-p-Menthenol(8) has a very penetrating and pleasant odour, which resembles and is even more pronounced than that of terpineol. Unlike the latter substance, it does not appear to yield a crystalline

* Later experiments on the conditions of formation of tertiary alcohols similar to $\Delta^{3}$-p-menthenol(8) have shown that a much better yield is always obtained when the ester employed is treated with rather less than the calculated quantity of magnesium methyl iodide.

Any excess of the latter acts as a dehydrating agent, and this accounts for the formation of such large quantities of $\Delta^{3.8(9)}-p$-menthadiene in the above experiment. 
nitrosochloride or phenylurethane, at all events under the experimental conditions employed by us.

Since ordinary terpineol is readily converted into crystalline terpin hydrate when left in contact with dilute sulphuric acid, an experiment on the action of dilute sulphuric acid on $\Delta^{3}-p$-menthenol( $(8)$ was carried out in the hope that a similar crystalline dihydroxycompound might result, but this did not prove to be the case. After 10 grams of the pure menthenol had been shaken on the machine with 1 litre of 5 per cent. sulphuric acid for 10 days, almost the whole of the substance was recovered unchanged on extraction with ether.

\section{$\Delta^{3.8(9)}-\mathrm{p}$-Menthadiene.}

This hydrocarbon is contained, together with some $\Delta^{3}-p$-menthenol(8), in the fractions of the product of the action of magnesium methyl iodide on ethyl tetrahydro- $p$-toluate, which distilled at $90-95^{\circ}(30 \mathrm{~mm}$., see the previous section). In order to decompose the menthenol which was present, the oil (17 grams) was digested with powdered potassium hydrogen sulphate (25 grams) in a reflux apparatus for one hour. After distilling in steam, the distillate was extracted with ether, the ethereal solution dried over calcium chloride and evaporated, and the residual oil distilled, the portion passing over at $178-190^{\circ}$ being collected separately. This oil was then twice fractionated and the fraction $\left(185-188^{\circ}\right)$ distilled three times over sodium and analysed:

$0 \cdot 1854$ gave $0.5690 \mathrm{CO}_{2}$ and $0 \cdot 1932 \mathrm{H}_{2} \mathrm{O} . \quad \mathrm{C}=87 \cdot 7 ; \mathrm{H}=11 \cdot 6$. $\mathrm{C}_{10} \mathrm{H}_{10}$ requires $\mathrm{C}=88.2 ; \mathrm{H}=11.8$ per cent.

$\Delta^{3.8(9)}-p$-Menthadiene boils at $186-187^{\circ}$ and possesses in a marked degree the intense odour of lemons so characteristic of dipentene; when cooled in liquid air, it solidifies to a glassy mass intersected with cracks, but the mass liquefies again at a temperature below $-40^{\circ}$. As the following experiment shows, it oxidises readily in the air, although apparently not so rapidly as dipentene. About 1 c.c. of the hydrocarbon was introduced into a tube standing over water, when it was found that in 6 days the water had risen 4.75 inches. Since the column of the original air was 24.5 inches in length, it follows that the absorption of the oxygen had been practically complete.

Action of Bromine.- $\Delta^{3.8(9)}-p$-Menthadiene is readily attacked by bromine, but, although it contains two double linkings, it is only capable of absorbing two atoms of bromine, as the following experiment shows (compare p. 641). The hydrocarbon (1.2 grams) was dissolved in chloroform (5 grams), the solution cooled to $-10^{\circ}$, and then bromine (diluted with twice its volume of chloroform) added slowly from a burette, every care being taken to keep the solution at $-10^{\circ}$ during the whole operation. At first, the colour of the bromine disappeared 
instantly, but as soon as the calculated quantity for thiew Online $\mathrm{C}_{10} \mathrm{H}_{16} \mathrm{Br}_{2}$ had been added the colour was very slowly discharged and then only with evolution of hydrogen bromide. A second experiment led to exactly the same result. The product from the two experiments was freed from chloroform by aspirating a rapid current of dry air through it, and analysed, after leaving for two days in an exhausted desiccator over caustic potash and paraffin wax.

$0 \cdot 2010$ gave $0 \cdot 2526 \mathrm{AgBr} . \quad \mathrm{Br}=53 \cdot 5$.

$$
\mathrm{C}_{10} \mathrm{H}_{16} \mathrm{Br}_{2} \text { requires } \mathrm{Br}=54 \cdot 0 \text { per cent. }
$$

This dibromide is readily acted on by zinc dust and acetic acid, but the reduction is a complicated one and we were unable to isolate any definite product.

Action of Hydrogen Chloride. - When freshly distilled $\Delta^{3.8(9)}-p$-menthadiene is dissolved in glacial acetic acid and saturated with hydrogen chloride at a temperature not exceeding $0^{\circ}$, it combines with the halogen acid to form the oily additive product, $\mathrm{C}_{10} \mathrm{H}_{16}, \mathrm{HCl}$.

After remaining for several hours, the solution was poured into ice water, rapidly extracted with ether, and the ethereal solution well washed with water and dilute sodium hydrogen carbonate. The bulk of the ether was then distilled off at as low a temperature as possible and the remainder removed over sulphuric acid in an exhausted desiccator. Unfortunately, although the experiment was repeated several times, the analysis always gave values which were considerably lower than those required by the formula $\mathrm{C}_{10} \mathrm{H}_{16}, \mathrm{HCl}$.

$$
\begin{aligned}
& 0.2902 \text { gave } 0.2178 \mathrm{AgCl} . \quad \mathrm{Cl}:=18 \cdot 7 . \\
& \qquad \mathrm{C}_{10} \mathrm{H}_{17} \mathrm{Cl} \text { requires } \mathrm{Cl}=20.5 \text { per cent. }
\end{aligned}
$$

Very probably this additive compound is unstable and loses some hydrogen chloride during the necessary washing with water and dilute sodium hydrogen carbonate.

Action of Hydrogen Bromide.-In investigating the behaviour of $\Delta^{3.8(9)}-p$-menthadiene towards hydrogen bromide, the hydrocarbon, directly after distillation, was shaken in a stoppered bottle with six times its volume of fuming hydrobromic acid (saturated at $0^{\circ}$ ), the temperature, which is apt to rise considerably, being kept below $10^{\circ}$ by cooling in ice water. After two hours, the product was poured into ice water, the heavy oil rapidly extracted with ether, the ethereal solution well washed with water, and the ether removed by careful evaporation and then over sulphuric acid in an exhausted desiccator. Two different preparations were analysed with the following results :

0.3807 gave $0.322 \mathrm{AgBr} . \quad \mathrm{Br}=36.0$.

0.3041 gave $0.2584 \mathrm{AgBr}$. $\mathrm{Br}=36 \cdot 2$.

$$
\mathrm{C}_{10} \mathrm{H}_{17} \mathrm{Br} \text { requires } \mathrm{Br}=36.9 \text { per cent. }
$$

VOL. LXXXVII. 
$\Delta^{3.8(9)}$-p-Menthadiene hydrobromide, when prepared in this View Online yellow oil which has an odour of oil of turpentine and is readily decomposed by boiling with water or dilute alkalis.

\section{p-Menthanol(8).}

This tertiary alcohol is produced when ethyl hexahydro- $p$-toluate reacts with magnesium methyl iodide.

Magnesium (8.4 grams) was suspended in dry ether and converted into magnesium methyl iodide in the usual way ; the well-cooled solution was then mixed with ethyl hexahydro- $p$-toluate ( 30 grams), care being taken to prevent rise of temperature.

After standing overnight, the product was carefully decomposed with water and dilute hydrochloric acid, the ethereal solution washed, evaporated, and the residue digested with methyl-alcoholic potash (8 grams of $\mathrm{KOH}$ ) for half an hour in order to remove any unchanged ester which might be present. After diluting with water, the oil was extracted with ether, the ethereal solution well washed, dried over calcium chloride, evaporated, and the oil fractionated under reduced pressure. Almost the whole quantity passed over at $99-101^{\circ}$ (20 mm.) as a colourless oil which, on cooling, solidified in long, flat plates. The crystals were left in contact with porous porcelain until quite dry and then analysed :

$$
\begin{gathered}
0.1680 \text { gave } 0.4712 \mathrm{CO}_{2} \text { and } 0.1940 \mathrm{H}_{2} \mathrm{O} . \quad \mathrm{C}=76.5 ; \mathrm{H}=12.8 . \\
\mathrm{C}_{10} \mathrm{H}_{20} \mathrm{O} \text { requires } \mathrm{C}=76.9 ; \mathrm{H}=12 \cdot 8 \text { per cent. }
\end{gathered}
$$

p-Menthanol(8) melts at about $35-36^{\circ}$ and is so soluble in the ordinary solvents that no attempt was made to recrystallise it; it distils at $206-207^{\circ}(750 \mathrm{~mm}$.) apparently without any decomposition, since the distillate solidifies at once on cooling. It volatilises rapidly at the ordinary temperature, and has a penetrating pleasant odour very similar to that of menthol, with which it is, of course, isomeric and closely allied in constitution.

\section{$\Delta^{8(9)}-\mathrm{p}-$ Menthene.}

This hydrocarbon is obtained when $p$-menthanol $(8)$ is digested with anhydrous potassium hydrogen sulphate.

The pure alcohol (25 grams) was mixed in a reflux apparatus with powdered potassium hydrogen sulphate ( 40 grams) and heated to boiling for two hours in an oil-bath. Sufficient water was then added to dissolve the salt, the oil was extracted with ether, and, after very carefully drying over calcium chloride and evaporating, several times fractionated in order to remove a considerable quantity of unchanged $p$-menthanol(8) which was present. The fraction $169-172^{\circ}$ was then 
distilled three times over sodium, when almost the whole quantity passed over at $170-170.5^{\circ}(746 \mathrm{~mm}$.).

$$
\begin{gathered}
0.1340 \text { gave } 0.4287 \mathrm{CO}_{2} \text { and } 0.1619 \mathrm{H}_{2} \mathrm{O} . \quad \mathrm{C}=87.2 ; \mathrm{H}=13.4 . \\
0.1478 \Rightarrow 0.4711 \mathrm{CO}_{2} " 0.1758 \mathrm{H}_{2} \mathrm{O} . \quad \mathrm{C}=86.9 ; \mathrm{H}=13.2 . \\
\mathrm{C}_{10} \mathrm{H}_{18} \text { requires } \mathrm{C}=87.0 ; \mathrm{H}=13.0 \text { per cent. }
\end{gathered}
$$

$\Delta^{8(9)}$-p-Menthene has a peculiar odour, which at first resembles parsley but is afterwards reminiscent of lemons. It does not appear to oxidise in the air, and when dissolved in chloroform and cooled to $-10^{\circ}$ it absorbs bromine without the evolution of hydrogen bromide. Several experiments were made in the hope of directly reducing $\Delta^{8(9)}$-p-menthene to $p$-menthane, but, although the hydrocarbon ( 7 grams) was treated in boiling alcoholic solution with 50 grams of sodium, only partial reduction took place, as the following analysis shows :

$$
\begin{gathered}
0.1132 \text { gave } 0.3581 \mathrm{CO}_{2} \text { and } 0.1395 \mathrm{H}_{2} \mathrm{O} . \quad \mathrm{C}=86.3 ; \mathrm{H}=13 \cdot 7 . \\
\text {-Menthane, } \mathrm{C}_{10} \mathrm{H}_{20} \text {, requires } \mathrm{C}=85 \cdot 7 ; \mathrm{H}=14.3 \text { per cent. }
\end{gathered}
$$

\section{8-Bromo-p-menthane, $\mathrm{Me} \cdot \mathrm{C}_{6} \mathrm{H}_{10} \cdot \mathrm{CBrMe}_{2}$, and $\mathrm{p}$-Menthane, $\mathrm{Me} \cdot \mathrm{C}_{6} \mathrm{H}_{10} \cdot \mathrm{CHMe}_{2}$.}

When $p$-menthanol $(8)$ is melted and then shaken in a tube with six times its volume of fuming hydrobromic acid (saturated at $0^{\circ}$ ), it appears at first to dissolve, but in a short time an oily layer separates on the surface of the hydrobromic acid. After one hour, the tube was sealed and heated at $50^{\circ}$ for about 15 minutes, the contents of the tube being several times well shaken. Water was then added, the heavy oil extracted with ether, the ethereal solution well washed with water, dried over calcium chloride, and the ether removed by evaporation at as low a temperature as possible and finally over sulphuric acid in an exhausted desiccator.

$$
\begin{aligned}
& 0.3197 \text { gave 0.276 } \mathrm{AgBr} \text {. } \mathrm{Br}=36.7 . \\
& \mathrm{C}_{10} \mathrm{H}_{19} \mathrm{Br} \text { requires } \mathrm{Br}=36.6 \text { per cent. }
\end{aligned}
$$

8-Bromo-p-menthane is a colourless oil which has an odour somewhat resembling that of isoamyl bromide; under $14 \mathrm{~mm}$. pressure, it appears to distil without much decomposition at about $110^{\circ}$, but no analysis of the distilled product was made. In reducing this bromo-compound to $p$-menthane, the oil was dissolved in 10 vols. of glacial acetic acid and treated first in the cold and then at $50^{\circ}$ with several small quantities of zinc dust, and after about half an hour the mass was heated on the water-bath with the addition of a few c.c. of a solution of hydrogen bromide in acetic acid. Water was then added, the oil extracted with ether, washed well with water, evaporated, and the reduction with zine dist and acetic acid repeated twice exactly as 
before. In order to be quite certain that the product was free from bromine, the oil (10 grams) was dissolved in alcohol (500 c.c.) and reduced at the boiling temperature with sodium (35 grams) in the usual way. After distilling in steam, the hydrocarbon was extracted with ether, twice distilled over sodium, and the fraction $\left(169-170^{\circ}\right)$ analysed:

0.1121 gave $0.3532 \mathrm{CO}_{2}$ and $0.1419 \mathrm{H}_{2} \mathrm{O} . \mathrm{C}=85.9 ; \mathrm{H}=14.0$. $p$-Menthane, $\mathrm{C}_{10} \mathrm{H}_{20}$, requires $\mathrm{C}=85 \cdot 7 ; \mathrm{H}=14 \cdot 3$ per cent.

The results of this analysis, and also the fact that the hydrocarbon reduced permanganate, showed clearly that the reduction had not been complete; the oil was therefore shaken on the machine with an excess of a 1 per cent. solution of potassium permanganate and a little caustic soda for 15 minutes, the hydrocarbon again extracted with ether and fractionated, when pure p-menthane was obtained distilling constantly at $169^{\circ}(758 \mathrm{~mm}$.$) .$

$0 \cdot 1416$ gave $0 \cdot 4442 \mathrm{CO}_{2}$ and $0 \cdot 1832 \mathrm{H}_{2} \mathrm{O} . \quad \mathrm{C}=85 \cdot 6 ; \mathrm{H}=14 \cdot 4$.

Berkenheim (Ber., 1892, 25, 688) found that $p$-menthane is produced when menthol is heated with hydriodic acid (sp. gr. 1.8) at $200^{\circ}$, and states that it boils at $169-170 \cdot 5^{\circ}$. Shortly afterwards, Wagner (Ber., 1894, 27, 1638) showed that this hydrocarbon may be much more conveniently prepared by treating menthol with concentrated sulphuric acid at the ordinary temperature. The sulphuric acid acts, in this instance, as a reducing agent, and the $p$-menthane obtained distilled at $168-169^{\circ}$.

Jünger and Klages (Ber., 1896, 29, 317) also prepared $p$-menthane from menthyl chloride by reduction with sodium and alcohol, but they do not give the boiling point of the hydrocarbon which they obtained in this way. Lastly, Sabatier and Senderens (Compt. rend., 1901, 132, $566)$ showed that $p$-menthane is produced when the vapour of cymene, mixed with hydrogen, is passed over reduced nickel at $180^{\circ}$, and they give the boiling point as $166-168^{\circ}$.

\section{p-Tolyldimethylcarbinol.}

The ethyl $p$-toluate required for the preparation of the above substance was obtained by heating $p$-toluic acid (100 grams) with alcohol (400 c.c.) and sulphuric acid ( 40 c.c.) on the water-bath for four hours. After isolating in the usual way, 106 grams of pure ester were obtained boiling at $229-230^{\circ}$. This ester (33 grams) was now added to an ethereal solution of magnesium methyl iodide (containing 9 grams of magnesium), all rise of temperature being avoided by cooling in running water. After twelve hours, the product was decomposed by wacer and dilute hydrochloric acid and the ethereal solution washed 

with water and evaporated. The oily residue was digested for half an hour with caustic potash (11 grams) dissolved in methyl alcohol, the neutral oil again precipitated by water and extracted with ether. The ethereal solution was well washed, dried over calcium chloride, evaporated, and the residual oil distilled under reduced pressure, when almost the whole quantity passed over at $111-112^{\circ}(16 \mathrm{~mm}$.$) .$

$$
\begin{gathered}
0.2292 \text { gave } 0.6714 \mathrm{CO}_{2} \text { and } 0.1908 \mathrm{H}_{2} \mathrm{O} . \quad \mathrm{C}=79.9 ; \mathrm{H}=9 \cdot 3 . \\
\mathrm{C}_{10} \mathrm{H}_{14} \mathrm{O} \text { requires } \mathrm{C}=80.0 ; \mathrm{H}=9.3 \text { per cent. }
\end{gathered}
$$

p-Tolyldimethylcarbinol has a rather pleasant sweet odour quite distinct from that of terpineol. Cooled in liquid air, it solidified to a glassy mass cracked all through, and this again became almost liquid at $-20^{\circ}$. When, however, the test-tube containing the substance was taken out of the liquid air and rubbed with a glass rod, the whole suddenly crystallised to an opaque solid at about $-20^{\circ}$; this gradually melted, and the melting point registered by a thermometer placed in the melting liquid was seen to be about $+5^{\circ}$.

$$
\begin{aligned}
& \mathrm{p} \text {-Tolyldimethylcarbinolphenylurethane, } \\
& \mathrm{Me}_{\mathrm{C}_{6}} \mathrm{C}_{4} \mathrm{H}_{4} \cdot \mathrm{CMe}_{2} \cdot \mathrm{O} \cdot \mathrm{CO} \cdot \mathrm{NH} \cdot \mathrm{C}_{6} \mathrm{H}_{5} .
\end{aligned}
$$

In preparing this derivative, the alcohol (3 grams) was mixed with phenylcarbimide ( 2.5 grams) in a small flask fitted with an air condenser, and after heating on the water-bath for three hours the liquid was allowed to stand for three days. The contents of the flask, which had become almost solid, were left in contact with porous porcelain until quite dry, and the residue purified by recrystallisation from dilute methyl alcohol.

$0 \cdot 1402$ gave $6 \cdot 6$ c.c. of nitrogen at $18^{\circ}$ and $760 \mathrm{~mm} . \quad \mathrm{N}=5 \cdot 4$. $\mathrm{C}_{17} \mathrm{H}_{19} \mathrm{O}_{2} \mathrm{~N}$ requires $\mathrm{N}=5 \cdot 2$ per cent.

This phenylurethane crystallises from dilute methyl alcohol in small needles and melts at $119-120^{\circ}$.

\section{p-Methylisopropenylbenzene.}

This hydrocarbon is readily prepared by acting on ethyl $p$-toluate with an excess of magnesium methyl iodide, when the latter acts as a dehydrating agent and converts a considerable quantity of the $p$-tolyldimethylcarbinol, first formed, into $p$-methylisopropenylbenzene.

The quantities actually employed were: ethyl $p$-toluate (33 grams), magnesium (14 grams), and methyl iodide (85 grams).

The reaction was allowed to proceed without cooling, and the product was isolated in the manner described on the preceding page.

The oil thus obtained, which consists of a mixture of hydrocarbon 
and alcohol, was digested for one hour with powdered potassium hydrogen sulphate in order to convert the alcohol into hydrocarbon, water was then added and the oil distilled in steam. The distillate was extracted with ether, the ethereal solution evaporated, and the residue fractionated, when almost the whole quantity passed over at $186-188^{\circ}$ (780 mm.).

The hydrocarbon was then twice distilled over sodium and analysed:

$$
\begin{gathered}
0.1508 \text { gave } 0.5014 \mathrm{CO}_{2} \text { and } 0.1227 \mathrm{H}_{2} \mathrm{O} . \quad \mathrm{C}=90.9 ; \mathrm{H}=9 \cdot 1 . \\
\mathrm{C}_{10} \mathrm{H}_{12} \text { requires } \mathrm{C}=90.9 ; \mathrm{H}=9.1 \text { per cent. }
\end{gathered}
$$

p-Methylisopropenylbenzene distils constantly at $187^{\circ}$ under $780 \mathrm{~mm}$. pressure and possesses an odour similar to that of cinnamene, but at the same time, especially when hot, it has a slight odour of lemons. When cooled in liquid air, the hydrocarbon solidified in definite leaflike crystals, and on removing the test-tube from the liquid air and allowing it to gradually melt a thermometer placed in the liquid indicated a melting point of approximately $-20^{\circ}$.

$p$-Methylisopropenylbenzene combines readily with two atoms of bromine, as the following experiment shows. The hydrocarbon ( $3.8 \mathrm{grams})$ was dissolved in two volumes of chloroform, cooled to $-10^{\circ}$, and a solution of bromine in two volumes of chloroform added until the colour remained permanent, when it was found that 4.4 grams of bromine had been absorbed, whereas the formation of a dibromo-addition product requires the absorption of 4.6 grams of bromine.

The chloroform was removed by aspirating a current of dry air through the solution, the oily residue allowed to remain for two days over paraffin wax and solid caustic potash in an exhausted desiccator, and analysed.

0.3064 gave 0.3906 AgBr. $\mathrm{Br}=54 \cdot 3$.

$$
\mathrm{C}_{10} \mathrm{H}_{12} \mathrm{Br}_{2} \text { requires } \mathrm{Br}=54 \cdot 7 \text { per cent. }
$$

p-Methyldibromoisopropenylbenzene rapidly becomes yellow on exposure to light and air. When distilled under $15 \mathrm{~mm}$. pressure, an oil passes over at $155-158^{\circ}$, which, however, contains only 45 per cent. of bromine, showing that some decomposition had taken place during the distillation.

The Nitrosochloride.-In preparing this derivative, the hydrocarbon ( 1 c.c.) was dissolved in methyl alcohol (1 c.c.), and after cooling to $-10^{\circ}$ mixed with isoamyl nitrite $(1.5$ c.c. $)$. Concentrated hydrochloric acid $(1 \cdot 1$ c.c.) and acetic acid $(0.5$ c.c.) were added drop by drop from a burette and the whole allowed to remain for one hour in the freezing mixture. When poured into ice water, an oil was precipitated, and when this had become almost solid it was left in contact with 

porous porcelain until quite dry, rapidly washed at the pump with a little methyl alcohol, and then recrystallised from this solvent.

$0 \cdot 1708$ gave 10.5 c.c. of nitrogen at $16^{\circ}$ and $746 \mathrm{~mm} . \quad \mathrm{N}=7 \cdot 0$. $\mathrm{C}_{10} \mathrm{H}_{12} \mathrm{NOCl}$ requires $\mathrm{N}=7 \cdot 1$ per cent.

p-Methyl isopropenylbenzene nitrosochloride melts at $100-102^{\circ}$ and is readily soluble in benzene or hot methyl alcohol, but sparingly so in light petroleum. It crystallises from a mixture of benzene and light petroleum in starry groups.

The Victoria University of Manchester. 